\title{
The effect of savory (Satureja khuzistanica) essential oils on performance, liver and kidney functions in broiler chickens
}

\author{
H. Khosravinia ${ }^{1,4}$, S. Ghasemi ${ }^{2}$ and E. Rafiei Alavi ${ }^{3}$ \\ ${ }^{1}$ Lorestan University, Faculty of Agriculture, Department of Animal Sciences, Khorramabad-68137-17133, Lorestan, Iran \\ ${ }^{2}$ Lorestan University, Faculty of Agriculture, Msc. scholar, Department of Animal Sciences, \\ Khorramabad-68137-17133, Lorestan, Iran \\ ${ }^{3}$ Lorestan University of Medical Sciences, Department of Pathology, Faculty of Medicine, Khorramabad 68138-33946, Iran
}

KEY WORDS: broiler chicken, savory essential oils, performance, liver, kidney

Received 1 June 2012

Revised 19 January 2013

Accepted 22 March 2013

${ }^{4}$ Corresponding author:

e-mail: khosravi_fafa@yahoo.com
ABSTRACT. This study was conducted to examine the effect of supplementation of 0 (control-) $0.5,1,1.5,2$, and $2.5 \mathrm{~g} \cdot \mathrm{I}^{-1}$ essential oils of Satureja khuzistanica (EOSk) or $3 \mathrm{~g} \cdot \mathrm{l}^{-1}$ polysorbate-80 (control+) into drinking water using 420 one-day-old Cobb 500 broiler chicks up to day 28 of age. The EOSktreated water significantly suppressed the productive performance of the birds $(P<0.05)$. Addition of EOSk to water at $2.5 \mathrm{~g} \cdot \mathrm{I}^{-1}$ caused significant increases in liver weight and serum glutamate pyruvate transaminase activity $(P<0.05)$. A significant decrease was found in the average serum uric acid concentration for the birds receiving water supplemented with EOSk at 0.5 to $2.5 \mathrm{~g} \cdot \mathrm{I}^{-1}$. It is concluded that persistent inclusion of EOSk at 0.5 to $2.5 \mathrm{~g} \cdot \mathrm{I}^{-1}$. into drinking water suppressed performance of broiler chickens during the early growth periods. No indication was found of hepato-suppressive effects of EOSk up to $g \cdot I^{-1}$.

\section{Introduction}

Satureja khuzistanica Jamzad, known as 'marzeh khuzestani' in Persian, is an endemic plant distributed in the southern part of Iran (Hadian et al., 2011). It is well known for its therapeutic values as an analgesic and antiseptic in traditional medicine (Zargari, 1990). A considerable level of essential oils, up to $4.5 \%$, has been identified as a prominent characteristic for this plant (Hadian et al., 2011). The essential oils of Satureja khuzistanica (EOSk) were reported to be peculiarly rich in carvacrol (Farsam et al., 2004). It has been also shown that EOSk contains a spectrum of phenols, flavones, triterpenoids, steroids, and tannins (Moghaddam et al., 2007). The extraordinarily high levels of carvacrol along with other beneficial biological properties of EOSk have made it a promising biological compound for pharmaceutical and food industries.

It has been reported that the essential oils of Satureja spp. have antiinflammatory (Hajhashemi et al., 2002), antispasmodic, antidiarrhea (Hajhashemi et al., 2000), and antioxidant (Abdollahi et al., 2003) effects in mammals, as well as antiviral (Yamasaki et al., 1998), antibacterial, and antifungal (Skocibusić and Bezić, 2004) effects, mainly in vitro.

These properties of Satureja khuzistanica have led into its domestication and cultivation by Khorraman Medical Plants Laboratory, (Khorramabad, Lorestan, Iran) since 2006. Consequently, the mass production of EOSk for commercial purposes has been achieved. Therefore, a reliable supply of the product is guaranteed for manufacturing of poultry feed and water additives. This experiment was con- 
ducted to assess the effect of high doses of EOSk on the performance of broiler chickens and their liver and kidney functions when administered through drinking water up to day 28 of age.

\section{Material and methods}

\section{Preparation of essential oils}

The aerial parts of plants cultivated at the Khorraman farm, Kashkan, Lorestan, Iran were collected during the flowering stage. The collected parts were air dried at ambient temperature in the shade. The dried materials were milled and then hydrodistilled using a Clevenger type apparatus for $5 \mathrm{~h}$, yielding $4 \%$ of a yellow oil. The oils were dried over anhydrous sodium sulfate and stored at $4{ }^{\circ} \mathrm{C}$. A bulk sample of the obtained essential oils was analyzed using the methods described by Hadian et al. (2011) and its composition is presented in Table 1.

Table 1. The composition of Satureja khuzistanica essential oils

\begin{tabular}{|c|c|c|c|}
\hline Compound & $\mathrm{RI}^{1}$ & Composition, \% & Identification $^{2}$ \\
\hline a-Thujene & 925 & $0.24 \pm 0.14$ & $\mathrm{RI}, \mathrm{MS}$ \\
\hline a-Pinene & 933 & $0.15 \pm 0.05$ & RI, MS, Col \\
\hline Myreene & 981 & $0.26 \pm 0.19$ & RI, MS \\
\hline a-Terpinene & 1013 & $0.24 \pm 0.12$ & RI, MS, Col \\
\hline p-Cymene & 1017 & $1.26 \pm 0.86$ & RI, MS, Col \\
\hline Limonene & 1026 & $0.13 \pm 0.04$ & RI, MS, Col \\
\hline (Z)-ß-oeimene & 1036 & $0.54 \pm 0.08$ & RI, MS \\
\hline Y-Terpenene & 1053 & $0.74 \pm 0.23$ & RI, MS, Col \\
\hline trans-Sabinene hydrate & 1081 & $0.17 \pm 0.02$ & RI, MS \\
\hline Terpin-4-ol & 1163 & $\operatorname{tr}$ & RI, MS \\
\hline a-terpinole & 1175 & $0.42 \pm 0.45$ & RI, MS \\
\hline Thymol & 1266 & $\operatorname{tr}$ & RI, MS, Col \\
\hline Carvacrol & 1282 & $92.16 \pm 0.46$ & RI, MS, Col \\
\hline Thymyl acetate & 1329 & $\operatorname{tr}$ & RI, MS \\
\hline$\beta$-caryophyllence & 1425 & $0.16 \pm 0.01$ & RI, MS, Col \\
\hline a-Humulene & 1427 & $\operatorname{tr}$ & $\mathrm{RI}, \mathrm{MS}$ \\
\hline$\beta$-Bisabolene & 1501 & $\operatorname{tr}$ & RI, MS \\
\hline Trans- $\beta$-bisabolene & 1522 & $0.10 \pm 0.01$ & RI, MS \\
\hline
\end{tabular}

\section{Experimental flock}

A total of 420 one-day-old Cobb 500 broiler chicks were provided by the Dorbar hatchery, Lorestan. The birds were randomly assigned to 21 pens $\left(90 \times 180 \mathrm{~cm}\right.$; at a density of $\left.0.08 \mathrm{~m}^{2} / \mathrm{bird}\right)$ arranged in three blocks, and bred up to 28 days of age. The pens were located in a cross-ventilated negative-pressure house equipped with infrared brooders. The temperature was set at $34^{\circ} \mathrm{C}$ in the first week and reduced to $30^{\circ}, 27^{\circ}$, and $24^{\circ} \mathrm{C}$ at the beginning of weeks 2, 3, and 4, respectively. Feed and water were supplied to the birds through a tube feeder and a manual waterer in each pen. Maize-
Table 2. Percentage inclusion and calculated composition of basal starter ( 1 to $21 \mathrm{~d}$ ) and grower ( 22 to $28 \mathrm{~d}$ ) diets

\begin{tabular}{lcc}
\hline Ingredient, \% & Starter & Grower \\
\hline Maize & 52.00 & 56.00 \\
Soyabean meal & 25.00 & 22.5 \\
Fish meal & 7.00 & 5.00 \\
Soyabean oil & 4.00 & 4.00 \\
Wheat & 3.50 & 3.50 \\
Calcium carbonate & 2.00 & 2.00 \\
Wheat bran & 2.50 & 3.00 \\
Dicalcium phosphate & 2.00 & 2.00 \\
DL-methoinine & 0.20 & 0.20 \\
L-lysine & 0.10 & 0.10 \\
Common salt & 0.25 & 0.25 \\
Mineral premix & 0.50 & 0.50 \\
Vitamin premix ${ }^{2}$ & 0.85 & 0.85 \\
Coccidiostat & 0.10 & 0.10 \\
Calculated composition & & \\
$\quad$ ME, Kcal · kg ${ }^{-1}$ & 3000 & 3150 \\
$\quad$ crude protein, \% & 22.24 & 20.02 \\
$\quad$ calcium, \% & 1.10 & 1.00 \\
available phosphorus, \% & 0.45 & 0.40 \\
methionine, \% & 0.52 & 0.40 \\
lysine, \% & 1.15 & 1.10 \\
\hline
\end{tabular}

${ }^{1}$ Mineral mix supplied/kg diet, mg: Mn 55, Zn 50, Fe 80, Cu 5, Se 0.1, I $0.18 ;{ }^{2}$ vitamin mix supplied. $\mathrm{kg}$ diet, IU: vit. A 18000 , vit. $\mathrm{D}_{3} 4000$; $\mathrm{mg}$ : vit. $E 36$, vit. $K_{3} 4$, vit. $B_{12} 0.03$, thiamine 1.8 , riboflavin 13.2 , pyridoxine 6 , niacin 60 , calcium pantothenate 20 , folic acid 2 , biotin 0.2 , choline chloride 500

and soyabean meal-based starter and grower diets (Table 2), in the form of mash and water, were provided to the birds for ad libitum consumption under a round-the-clock lighting regime. Seven experimental treatments were based on supplementing drinking water with 0 (control-), $0.5,1,1.5,2$, and $2.5 \mathrm{~g} \cdot 1^{-1}$ EOSk or $3 \mathrm{~g} \cdot 1^{-1}$ Polysorbate- 80 (control+). Polysorbate-80 is an emulsifier which was used to dissolve EOSk in water at a 2:1 ratio $(\mathrm{v} / \mathrm{v})$.

\section{Data collection}

The weight of the birds, feed intake (FI), and water consumption (WC) were recorded weekly from day 1 to 28 of the experiment; mortality was registered daily. Water consumption was measured by providing a predetermined volume of EOSkcontaining water for each treatment in a separate tank at the commencement of each week. At the end of a week, the remaining water in each tank, as well as residual water in the corresponding waterers, was subtracted from the initial volume. Feed intake was measured by subtracting the residual feed for each pen from the total feed provided in a week. The data on feed and water intake were adjusted for mortality cases. The average daily weight gain (ADWG), feed intake (ADFI), water intake (WC), and feed 
conversion ratio (FCR) were calculated per day per bird. On day 28, two male and two female chickens per pen (12 birds per treatment) were slaughtered and manually processed to determine carcass yield and the liver-to-carcass weight ratio. Blood samples (4 ml) were collected from all killed birds for determination of serum enzymes, including serum glutamate pyruvate transaminase (SGPT), serum glutamate oxaloacetate transaminase (SGOT), and serum alkaline phosphatase (SALP). The concentrations of SGPT and SGOT were assessed based on the IFCC method without pyridoxal phosphate (P-5-P) as described by Bergmeyer et al. (1986). SALP was measured based on the DGKC method (Anonymous, 1972) with slight modifications as adopted by SCE (Anonymous, 1974). The serum samples were also examined for concentration of urea, uric acid, and creatinine using an automatic analyzer (Selects E Autoanlyzer, Sr. No. 8-7140, Vital Company, Netherlands), following the instructions for commercial kits (SEPPIM S.A.S., Zone Industrielle, 61500, SEES, France) at $25^{\circ} \mathrm{C}$.

\section{Statistical analysis}

The data were analyzed using PROC MIXED of SAS 9.1 (SAS, 2002). The statistical model used was:

$$
Y_{i j}=\mu+E O_{i}+B_{j}+\varepsilon_{i j}
$$

where: $Y_{i j}$ is the dependent variable, $\mu$ is the general mean, $E O_{i}$ is the fixed effect of EOSk $\left(i=7\right.$; cont-, cont $\left.+, 0.5,1,1.5,2,2.5 \mathrm{~g} \cdot 1^{-1}\right), B$ is the random effect of block $(j=3 ; 1,2$ and 3$)$ and $\varepsilon_{i j}$ is the residual error. The LSD test was used for multiple treatment comparisons using the LSMEANS statement of SAS 9.1 (SAS, 2002) with letter grouping obtained using the SAS pdmix 800 macro (Saxton, 1998). For the different statistical tests, significance was declared at $\mathrm{P} \leq 0.05$, unless otherwise stated. The REG procedure of SAS 9.1 (SAS Institute, 2002) was used to provide regression models for assessment of the relation between EOSk and weight gain as well as water consumption.

\section{Results}

Performance data for the $1-7 \mathrm{~d}, 8-14 \mathrm{~d}, 15-21$ $\mathrm{d}$, and 22-28 d periods were gathered and analyzed. Only performance data for the $1-28 \mathrm{~d}$ period are reported (Table 3).

A significant treatment effect was observed. for ADWG $(\mathrm{P}=0.0001)$, FI $(\mathrm{P}=0.0169)$, FCR $(\mathrm{P}=0.0001)$, WC $(\mathrm{P}=0.0001)$, and FI:WC ratio $(\mathrm{P}=0.0001)$ during the course of the experiment. All through the experiment, EOSk-treated water decreased ADWG and WC in a dose-dependent, linear manner in comparison with the control birds. High negative associations were found between cumulative live weight vs. the level of EOSk at 7, 14, 21, and 28 days of age. For each $0.5 \mathrm{~g} \cdot 1^{-1}$ increase in EOSk in drinking water, the live weight of the birds was decreased by $4.11,14.69,36.14$, and $61.31 \mathrm{~g}$ during periods $1-7,8-14,15-21$, and 22-28 days of age, respectively, compared with the control birds (Figure 1)

Adecreasing linear association was also observed between water consumption and EOSk level at 7, 14, 21, and 28 days of age (Figure 2). Feed intake, FCR, and the FI:WC ratio were also significantly reduced for the birds receiving treated water in comparison with the control birds. Nonetheless, no consistent diminishing trend in all three variables was found by increasing levels of EOSk in drinking water (Table 3). The mortality data were not analyzed since during the trial only 2 chickens died in the the $1.5 \mathrm{~g}$ $1^{-1}$ and 1 chicken in $1 \mathrm{~g} . \mathrm{l}^{-1}$ EOSk treatments.

Table 3. Effect of Satureja khuzistanica essential oils (EOSk) on average daily weight gain (ADWG, g), average daily feed intake (ADFI, g), feed conversion ratio (FCR = ADFI /ADWG), water consumption (WC, $\mathrm{ml}$. day . $\mathrm{b}^{-1}$ )

\begin{tabular}{|c|c|c|c|c|c|c|c|c|c|}
\hline & \multirow[b]{2}{*}{ Cont $^{2}{ }^{2}$} & \multirow[b]{2}{*}{ Cont- $^{2}$} & \multicolumn{5}{|c|}{ EOSk, $g \cdot l^{-1}$} & \multirow{2}{*}{$\mathrm{SEM}^{3}$} & \multirow{2}{*}{$P>F$} \\
\hline & & & 0.5 & 1 & 1.5 & 2 & 2.5 & & \\
\hline$\overline{A D W G}$ & $40.86^{\mathrm{ab}}$ & $42.35^{a}$ & $39.64^{b}$ & $36.52^{c}$ & $34.83^{c}$ & $33.06^{d}$ & $31.56^{d}$ & 0.866 & 0.0001 \\
\hline ADFI & $68.42^{\mathrm{bc}}$ & $67.89^{\circ}$ & $69.80^{\mathrm{ab}}$ & $69.95^{\mathrm{ab}}$ & $68.68^{\mathrm{abc}}$ & $67.10^{c}$ & $70.25^{\mathrm{a}}$ & 0.308 & 0.0169 \\
\hline FCR & $1.67^{c d}$ & $1.60^{\mathrm{d}}$ & $1.76^{c}$ & $1.92^{b}$ & $1.97^{b}$ & $2.03^{a}$ & $2.23^{a}$ & 0.047 & 0.0001 \\
\hline WC & $212.35^{a}$ & $209.88^{b}$ & $166.24^{c}$ & $155.83^{d}$ & $148.52^{\mathrm{e}}$ & $147.17^{f}$ & $135.7^{9}$ & 6.395 & 0.0001 \\
\hline WC: FI & $3.44^{\mathrm{a}}$ & $3.24^{b}$ & $2.73^{c}$ & $2.57^{d}$ & $2.47^{\mathrm{e}}$ & $2.51^{\text {de }}$ & $2.32^{f}$ & 0.087 & 0.0001 \\
\hline
\end{tabular}

${ }^{1}$ Each figure is the mean for three experimental replicates consisting one pen of 20 birds each; ${ }^{2}$ control+ birds received drinking water supplemented with $3 \mathrm{~g} \cdot \mathrm{I}^{-1}$ polysorbate-80 throughout the trial. control- birds received drinking water with no additive; ${ }^{3}$ standard error for overall mean; ${ }^{a-g}$ means within a row with different superscripts differ significantly $(P<0.05)$ 


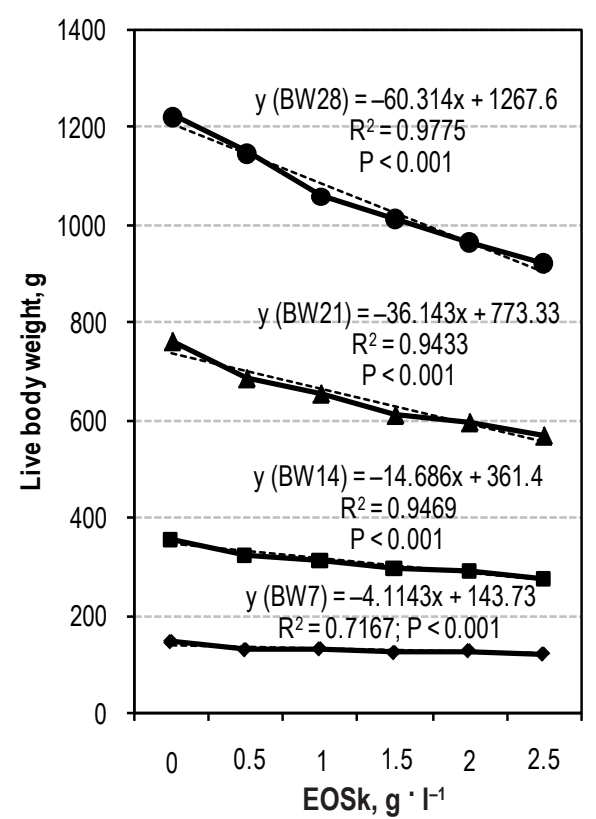

Figure 1. Effect of Satureja khuzistanica essential oils (EOSk) on cumulative live body weight (BW) in broiler chickens at 7, 14, 21 and 28 days of age

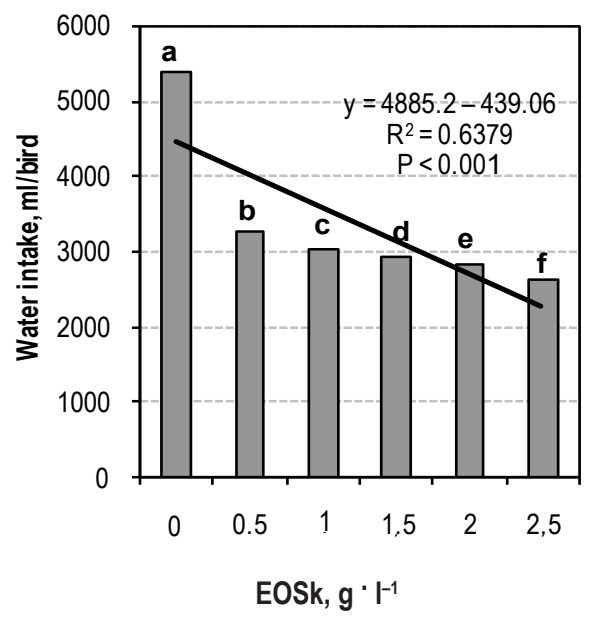

Figure 2. Effect of Satureja khuzistanica essential oils (EOSk) on water intake, $\mathrm{ml} / \mathrm{bird}$ in broiler chickens during 1 to 28 days of age

No change in liver weight or in serum enzyme concentrations, including SGPT, SGOT, and SALP (Table 4), or serum biochemical parameters (Table 5) were observed in the chickens receiving EOSk-supplemented water up to $2 \mathrm{~g} \cdot 1^{-1}$ compared with the control groups $(\mathrm{P}>0.05)$. To offset the effects of varying live weight, the liver weight was reported as a percentage of carcass weight (Table 4).

Addition of EOSk in water at $2.5 \mathrm{~g} \cdot 1^{-1}$ significant ly increased the liver weight percentage compared with the birds receiving lower levels of ESOk. No significant differences were observed in SALP and SGOT between the birds receiving either normal or treated water $(\mathrm{P}>0.05)$. The mean concentration of SGPT, however, was numerically greater in the birds
Table 4. Effect of Satureja khuzistanica essential oils on liver relative weight (as a percentage of carcass weight), and liver enzymes ${ }^{1}$ in broiler chickens at 28 days of age

\begin{tabular}{|c|c|c|c|c|c|}
\hline Factorllevel & $\mathrm{n}$ & $\begin{array}{l}\text { Liver } \\
\text { weight, \% }\end{array}$ & $\begin{array}{l}\text { SALP, } \\
\mathrm{IU} \cdot \mathrm{dl}^{-1}\end{array}$ & $\begin{array}{l}\text { SGPT, } \\
\mathrm{IU} \cdot \mathrm{dl}^{-1}\end{array}$ & $\begin{array}{l}\text { SGOT, } \\
\mathrm{IU} \cdot \mathrm{dl}^{-1}\end{array}$ \\
\hline \multicolumn{6}{|l|}{ EOSk, $\mathrm{g} \cdot \mathrm{I}^{-1}$} \\
\hline control+ ${ }^{2}$ & 12 & 2.44 & 73.90 & 2.92 & 259.75 \\
\hline control- ${ }^{2}$ & 12 & 2.42 & 69.78 & 3.67 & 261.75 \\
\hline 0.5 & 12 & 2.52 & 80.43 & 3.50 & 256.58 \\
\hline 1 & 12 & 2.68 & 54.64 & 2.97 & 267.25 \\
\hline 1.5 & 12 & 2.60 & 61.51 & 3.27 & 248.64 \\
\hline 2 & 12 & 2.60 & 57.20 & 3.33 & 242.58 \\
\hline 2.5 & 12 & 2.80 & 60.24 & 4.25 & 231.67 \\
\hline \multicolumn{6}{|l|}{ Sex } \\
\hline male & 42 & 2.57 & 68.28 & 3.49 & 254.21 \\
\hline female & 42 & 2.60 & 62.38 & 3.25 & 260.65 \\
\hline \multirow[t]{2}{*}{$\mathrm{SEM}^{3}$} & & 0.05 & 4.17 & 0.33 & 5.19 \\
\hline & & \multicolumn{4}{|c|}{$P>F$} \\
\hline EOSk & & 0.4386 & 0.4115 & 0.8800 & 0.6631 \\
\hline Sex & & 0.6347 & 0.3146 & 0.6210 & 0.1312 \\
\hline EOSk $\times$ Sex & & 0.7975 & 0.1405 & 0.3961 & 0.5555 \\
\hline
\end{tabular}

1 Serum Alkaline Phosphatase (SALP), Serum Glutamate Pyruvate Transaminase (SGPT) and Serum Glutamate Oxaloacetate Transaminase (SGOT); ${ }^{2}$ control+ birds received drinking water supplemented

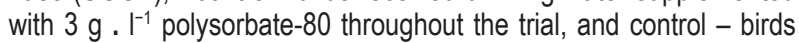
received drinking water with no additive; ${ }^{3}$ standard error for overall mean

receiving EOSk-treated water at $2.5 \mathrm{~g} \cdot 1^{-1}$ compared with those bred on normal water (4.25 vs. 3.67 IU $\left.\cdot 1^{-1}\right)$. Neither gender nor the interaction of gender and EOSk level had an effect on mean liver weight, SALP, SGPT, or SGOT (Table 4).

Inclusion of $0.5 \mathrm{~g} \cdot 1^{-1} \mathrm{EOSk}$ in drinking water resulted in a significant decrease in average serum the control birds (Table 5). No dose-dependent change in the same variable was observed by increasing levels of EOSk, however. At 28 days of age, no significant differences in average serum urea $\left(\mathrm{mg} \cdot \mathrm{dl}^{-1}\right)$ were found among the birds receiving ed either normal or EOSk-supplemented water $(\mathrm{P}>$ 0.05 ; Table 5). The mean serum creatinine was lower for the birds receiving $2.5 \mathrm{~g} \cdot \mathrm{1}^{-1}$ EOSk in their water compared with the other treatments. There were no significant differences, however, among the mean serum creatinine concentration in all the birds. In both sexes, the mean serum concentrations of uric acid, urea, and creatinine did not significantly differ among the experimental treatments. No significant sex $\times$ EOSk interactions were identified for the same variables (Table 5). 
Table 5. Effect of Satureja khuzistanica essential oils (EOSk) on serum concentration of uric acid, urea and creatinine in broiler chickens at day 28 of age

\begin{tabular}{lllll}
\hline Factor/level & $\mathrm{n}$ & $\begin{array}{l}\text { Uric acid, } \\
\mathrm{mg} \cdot \mathrm{dl}^{-1}\end{array}$ & $\begin{array}{l}\text { Urea, } \\
\mathrm{mg} \cdot \mathrm{dl}^{-1}\end{array}$ & $\begin{array}{l}\text { Creatinine, } \\
\mathrm{mg} \cdot \mathrm{dl}^{-1}\end{array}$ \\
\hline $\begin{array}{l}\text { EOSk, } \mathrm{g} \cdot \mathrm{l}^{-1} \\
\text { control+ }^{1}\end{array}$ & 12 & $4.82^{\mathrm{ab}}$ & 3.00 & 0.275 \\
control-1 $^{1}$ & 12 & $5.11^{\mathrm{a}}$ & 2.92 & 0.283 \\
0.5 & 12 & $3.08^{\mathrm{b}}$ & 3.58 & 0.283 \\
1 & 12 & $4.05^{\mathrm{b}}$ & 3.58 & 0.292 \\
1.5 & 12 & $3.37^{\mathrm{b}}$ & 3.27 & 0.318 \\
2 & 12 & $3.98^{\mathrm{b}}$ & 3.50 & 0.262 \\
2.5 & 12 & $3.72^{\mathrm{b}}$ & 3.17 & 0.233 \\
Sex & & & & \\
male & 42 & 4.28 & 3.16 & 0.27 \\
female & 42 & 3.75 & 3.43 & 0.28 \\
SEM ${ }^{2}$ & & 0.02 & 0.12 & 0.01 \\
& & & $\mathrm{P}>\mathrm{F}$ & \\
EOSk & & 0.0495 & 0.6763 & 0.1241 \\
Sex & & 0.0621 & 0.2153 & 0.6768 \\
EOSk $\times$ sex & & 0.1733 & 0.8295 & 0.8839 \\
\hline
\end{tabular}

${ }^{1}$ Control+ birds received drinking water supplemented with $3 \mathrm{~g} \cdot \mathrm{I}^{-1}$ polysorbate-80 throughout the trial, control-birds received drinking water with no additive; ${ }^{2}$ standard error for overall mean; ${ }^{a-b}$ means within a column with different superscripts differ significantly $(P<0.05)$

\section{Discussion}

The results pertaining to the performance of the birds clearly indicated that continual supplementation of EOSk into drinking water adversely affected ADWG, the main economic parameter in broiler chicken production. This effect can be indisputably attributed to reduced water consumption by the birds receiving treated water. Adequate water consumption is critical for fastgrowing broiler chickens, especially when they are reared in high ambient temperatures. The birds kept on treated water showed greater feed intake (about 1\%-2\%) compared with the control groups, however, the consumed feed was not efficiently digested and/ or utilized by these birds, as demonstrated by their increased FCR. The worse FCR values in the treated birds may be associated with unfavorable effects of EOSk on gut function. No plausible interpretation can be given, however, based on the results obtained in the present study, except for the gut content $\mathrm{pH}$, which was not significantly different in various gut segments among the experimental treatments (data not presented). EOSk consists of a wide range of volatile lipophilic compounds, including carvacrol, which comprises more than $92 \%$ of the entire extract. This monoterpenoid phenol is bitter-tasting and pungent, which obviously changed the flavor of water and caused significantly reduced water consumption in broilers. No data were found in the literature at hand on the possible effects of adding EOSk to drinking water in farm animals. Doserelated depression of palatability was reported in pigs fed essential oils from fennel and caraway, as well as from the herbs thyme and oregano (Schöne et al., 2006). Lee et al. (2003) reported that inclusion of $0.2 \mathrm{~g} \cdot \mathrm{kg}^{-1}$ carvacrol in broiler diets resulted in a $2 \%$ increase in feed intake and average daily gain and a $1 \%$ decrease in FCR. Addition of thymol, an isomer of carvacrol, at the same dose caused greater reduction in all three parameters by $5 \%, 3 \%$ and $3 \%$, respectively. In an overview on feeding phytogenic compounds, Windisch et al. (2008) reported that the majority of experimental results indicate reduced feed intake at largely unchanged body weight gain or final body weight, leading to an improved feed conversion ratio. Therefore, the findings of the present study, in concord with the conclusion drawn by Windisch et al. (2008), support the statement that it is generally not justified to assume that phytogenic extracts improve the palatability of feed.

The liver is the primary organ perfused by chemicals absorbed in the gut and is the first organ that may be affected by the toxic properties of the absorbed agents. A noticeable indication of hepatic damage is leaking of cellular enzymes into the plasma (Schmidt and Schmidt, 1983), which is due to instability in the transport functions of hepatocytes (Zantop, 1997). The estimation of serum marker enzymes is a useful quantitative marker of the extent and type of hepatocellular damage in chicken, as well as many other species exposed to toxic substances through feed (Huff et al., 1988; Celyk et al., 2003) and water (Wu, 1997). When the plasma membrane of a hepatocyte is injured, a variety of cytosolic enzymes will be released into the circulation, thus causing increased enzyme levels in the serum. In the present study, constant exposure of the chickens from 1 to 28 days to EOSK doses greater than $2 \mathrm{~g} \cdot 1^{-1}$ increased the workload of the liver and reduced its capacity to detoxify chemical compounds.

Kidneys usually are the second target organ that may be damaged by toxins absorbed through the gut. In avian species, evaluation of kidney function is based on serum concentrations of uric acid, urea, and creatinine (Selvaraj et al., 1998). Huff et al. (1988) confirmed that significant increases in serum uric acid and creatinine levels are indicative of 
nephrotoxicity in broiler chickens. Among them, uric acid is of prime importance. Like other birds, broiler chickens are urecotelic and eliminate $60 \%-80 \%$ of nitrogen in the form of uric acid. Among many other factors, serum levels of this acid fluctuate with (Costa et al., 1993), water consumption, and kidney health in terms of filtration rate. In the present study, consistent low levels of serum uric acid of the birds receiving treated water (at doses from 0.5 to $2.5 \mathrm{~g} \cdot 1^{-1}$ ) showed, at first glance, better renal filtration for the same molecules. The reduced water consumption accompanying the nonsignificant increase in serum urea and vacillating creatinine levels, however, raised doubts on this interpretation. It should be noted that inclusion of EOSk in drinking water of broiler chicks may cause improper kidney function.

\section{Conclusions}

The results of the present study demonstrated that continual supplementation of drinking water with EOSk at 0.5 to $2.5 \mathrm{~g} \cdot 1^{-1}$ suppress weight gain and the feed conversion ratio in broiler chicks during the early growth periods, most likely due to reduced water consumption. There was no indication of negative effects of EOSk on the livers of broiler chickens up to $2 \mathrm{~g} \cdot 1^{-1}$, but at $2.5 \mathrm{~g} \cdot 1^{-1}$ liver dysfunction occurred.

\section{References}

Abdollahi M., Salehnia A., Mortazavi S.H., Ebrahimi M., Shafiee A., Fouladian F. Keshavarz K., Sorouri S., Khorasani R., Kazemi A., 2003. Antioxidant, antidiabetic, antihyperlipidemic, reproduction stimulatory properties and safety of essential oil of Satureja Khuzistanica in rat in vivo: a toxicopharmacological study. Med. Sci. Monit., 9, 331-335

Anonymous, 1972. Determination of serum alkaline phosphatase. German Society for Clinical Chemistry. Z. Klin. Chem. Klin. Biochem. 10, 281

Anonymous, 1974 Assessment of serum alkaline phosphatase. Committee on Enzymes of the Scandinavian Society for Clinical Chemistry and Clinical Physiology. Scand. J. Clin. Lab. Invest.. 33, 291

Bergmeyer H.U., Hørder M., Rej R., 1986. IFCC method for aspartate aminotrasferase. Part 2., J. Clin. Chem. Clin. Biochem. 24, 497-510

Celyk K., Denly M., Savas T., 2003. Reduction of toxic effects of aflatoxin $B_{1}$ by using baker yeast (Saccharomyces cerevisiae) in growing broiler chicks diet. R. Bras. Zootec. 32, 615-619

Costa N.D., McDonald D.E., Swan R.A., 1993. Age-related changes in plasma biochemical values of farmed emus (Dromaius novaehollandie). Aust. Vet. J. 70, 341-344
Farsam H., Amanlou M., Radpour M.R., Salehnia A.N., Shafiee A., 2004. Composition of the essential oils of wild and cultivated Satureja khuzistanica Jamzad form Iran. Flavour Fragr. J. 19,308-310

Hadian J., Mirjalili M.H., Kanani M.R., Salehnia A., Ganjipoor P., 2011. Phytochemical and morphological characterization of Satureja khuzistanica Jamzad populations from Iran. Chemist. and Biodiver. 8, 902-915 19,308-310

Hajhashemi V., Ghannadi A., Pezeshkian S.K., 2002. Antinociceptive and anti-inflammatory effects of Satureja hortensis L. extracts and essential oil. J. Ethnopharmacol. 82, 83-87

Hajhashemi V., Sadraei H., Ghannadi A.R., Mohseni M., 2000. Antispasmodic and anti-diarrhoeal effect of Satureja hortensis L. essential oil. J. Ethnopharmacol. 71, 187-192

Huff W.E., Kubena L.F., Harvey R.B., 1988. Progression of ochratoxicosis in broiler chickens. Poultry Sci. 67, 1139-1146

Lee K.-W., Everts H., Kappert H.J., Frehner M., Losa R., Beynen A.C., 2003. Effects of dietary essential oil components on growth performance, digestive enzymes and lipid metabolism in female broiler chickens. Brit. Poultry Sci. 44, 450-457

Moghaddam F.M., Farimiani M.M., Salahvarzi S., Amin G., 2007. Chemical constituents of dichloromethane extract of cultivated Satureja khuzistanica. Evid. Based Complement. Altern. Med. 4, 95-98

SAS, 2002. SAS/STAT ${ }^{\circledR}$ Guide for personal computers. Version 9.1. SAS Institute, Inc., Cary, NC

Saxton A.M., 1998. A macro for converting mean separation output to letter grouping in Proc Mixed. In Proc. 23 ${ }^{\text {rd }}$ SAS User Group Int. SAS Institute, Cary, NC, 1243-1246

Schmidt E., Schmidt F.W., 1983. Glutamate dehydrogenase. In: Methods of Enzymatic Analysis, $3^{\text {th }}$ Edition. U. Bergmeyer (Editor). Academic Press, New York, pp. 216-217

Schöne F., Vetter A., Hartung $H_{\text {., }}$ Bergmann $H_{\text {., }}$ Biertümpfel A., Richter G., Müller, S., Breitschuh G., 2006. Effects of essential oils from fennel (Foeniculi aetheroleum) and caraway (Carvi aetheroleum) in pigs. J. Anim. Physiol. Anim. Nutr. 90, 500-510

Selvaraj P., Thangavel A., Nanjappan K., 1998. Plasma biochemical profile of broiler chickens. Indian Vet. J. 75, 1026-1027

Skocibusić M., Bezić N., 2004. Phytochemical analysis and in vitro antimicrobial activity of two Satureja species essential oils. Phytother Res. 18, 967-970

Windisch W., Schedle K., Plitzner C., Kroismayr A., 2008. Use of phytogenic products as feed additives for swine and poultry. J. Anim. Sci. 86, 140-148

Wu W., 1997. Counteracting Fusarium proliferatum toxicity in broiler chicks by supplementing drinking water with Poultry Aid Plus ${ }^{\circledR}$. Poultry Sci. 76, 463-468

Yamasaki K., Nakano M., Kawahata T., Mori H., Otake T., Ueba N., Oishi I., Inami R., Yamane M., Nakamura M., Murata H., Nakanishi T., 1998. Anti-HIV-1 activity of herbs in Labiatae. Biol. Pharm. Bull. 21, 829-833

Zantop D.W., 1997. Biochemistries. In Avian Medicine: Principles and Applications. B.W. Ritchie, G.J. Harrison, L.R. Harrison (Editors). Wingers Publishing Inc., Lake Worth, FL, 115-129

Zargari A., 1990. Medicinal Plants. $4^{\text {th }}$ Edition. Tehran University Publications, Tehran, pp. 42-45Hajhashemi V., Sadraei H., Ghannadi A.R., Mohseni M., 2000. Antispasmodic and antidiarrhoeal effect of Satureja hortensis L. essential oil. J. Ethnopharmacol. 71, 187-192 